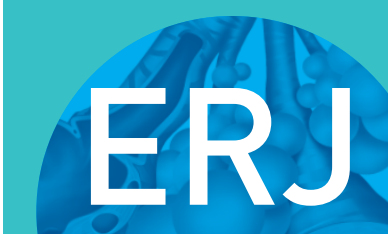

open research

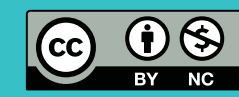

\title{
Predictors of prolongation in recent-onset cough
}

\author{
Anne M. Lätti (i] ${ }^{1,2}$, Juha Pekkanen ${ }^{3,4}$ and Heikki O. Koskela (10 ${ }^{1,2}$
}

Affiliations: ${ }^{1}$ Unit for Medicine and Clinical Research, Pulmonary Division, Kuopio University Hospital, Kuopio, Finland. ${ }^{2}$ School of Medicine, Institute of Clinical Sciences, Faculty of Health Sciences, University of Eastern Finland, Kuopio, Finland. ${ }^{3}$ Dept of Public Health, University of Helsinki, Helsinki, Finland. ${ }^{4}$ Environmental Health Unit, National Institute for Health and Welfare, Kuopio, Finland.

Correspondence: Anne M. Lätti, Unit for Medicine and Clinical Research, Pulmonary Division, Kuopio University Hospital, Kuopio, PL 100, 70029 KYS, Finland. E-mail: anne.lattiakuh.fi

ABSTRACT Chronic cough greatly decreases the quality of life and is often refractory to treatment. Interventions at an early stage could prevent cough from becoming chronic. To this end, the patients at high risk of cough prolongation would need to be identified. In this study, we investigated the factors that predicted cough at 12 months among subjects with a recent-onset cough.

This was a prospective, observational follow-up study in a community-based population consisting of working-age subjects. The first e-mail survey in 2017 included a comprehensive questionnaire about current cough and its risk factors. The 259 subjects who reported a recent-onset $(<8$ weeks) cough were sent a follow-up questionnaire 12 months later.

The response rate was $72.6 \%$ (188 subjects). There were 99 subjects $(52.7 \%)$ with cough in 2018 . The following baseline factors predicted the presence of any cough at 12 months in the multivariable analysis: wheezing (adjusted odds ratio (aOR 2.80, 95\% CI 1.3-5.27), dog ownership (aOR 2.56, 95\% CI 1.21-5.44), cough duration $>3$ weeks (aOR 2.29, 95\% CI 1.11-4.76), family history of chronic cough (aOR 2.20, 95\% CI 1.13-4.30), body mass index $>25 \mathrm{~kg} \cdot \mathrm{m}^{-2}$ (aOR 2.06, 95\% CI 1.02-4.15) and frequent somatic symptoms (aOR 1.36, 95\% CI 1.13--1.64). There were 29 subjects (15.4\%) with continuous cough and 66 subjects $(35.1 \%)$ with recurrent cough. The risk factors were completely different between recurrent and continuous cough.

It may be possible to identify the risk factors of cough prolongation among subjects with recent-onset cough. Early interventions should be targeted to these kinds of patients.

@ERSpublications

Interventions targeted at an early stage of cough could prevent that cough from becoming chronic. To this end, it would be necessary to be able to identify patients who have recent-onset cough and who are at high risk of developing chronic cough. http://bit.ly/2 VNqxCv

Cite this article as: Lätti AM, Pekkanen J, Koskela HO. Predictors of prolongation in recent-onset cough. ERJ Open Res 2019; 5: 00238-2018 [https://doi.org/10.1183/23120541.00238-2018].

This article has supplementary material available from openres.ersjournals.com

Received: Dec 102018 | Accepted after revision: March 262019

Copyright $\odot$ ERS 2019. This article is open access and distributed under the terms of the Creative Commons Attribution Non-Commercial Licence 4.0. 


\section{Introduction}

Chronic cough is a common [1] and troublesome disorder [2] that often has a poor prognosis [3] despite extensive investigation and treatment trials [4]. The mechanisms behind chronic cough are unclear but it has been proposed that there remains an enhancement of the cough reflex similar to chronic neuropathic pain. At present, this condition is called the chronic cough hypersensitivity syndrome $[5,6]$. Therefore, it would be necessary to be able to identify patients who have recent-onset cough and who are at a high risk of developing cough prolongation. We postulated that interventions targeted at an early stage of the cough could prevent the long-standing abnormality in cough reflex function. In this study, we examined the factors that predicted the presence of any cough at 12 months in those subjects with recent-onset cough. Based on the findings of our previous article [7], two further endpoints were chosen: 1) prolongation of the same cough episode up to 12 months and 2) recurrence of cough.

\section{Methods}

\section{Study design and population}

This was a prospective, observational follow-up study conducted in public service employees of two middle-sized towns in central Finland (Kuopio and Jyväskylä, 13980 employees, mean age 46.6 years, $79.2 \%$ females). An invitation to the study and the first questionnaire were sent via e-mail to the employees' e-mail addresses in March-April 2017. Answers were collected via an electronic reply form. One reminder message was sent if a subject had not responded within 2 weeks. A total of 3697 subjects (26.4\%) responded and $546(14.8 \%)$ of them reported suffering from recent-onset $(<8$ weeks) cough. The second questionnaire was sent via e-mail in April 2018 to all the participants who had been suffering from recent-onset cough during the first inquiry in 2017 and who had provided permission for follow-up ( $\mathrm{n}=259$, mean (95\% CI) age 49.2 (10.4) years, 85.3\% females) (figure 1). One reminder message was sent if a subject had not responded within 2 weeks. One telephone contact was made if a subject had not answered within 2 weeks after the reminder message.

The study was approved by the Ethics Committee of Kuopio University Hospital (289/2015). Permission to conduct the study was obtained from town officials. The invitation mail requesting participation in the study included detailed information about the study. The decision of the subject to reply was considered informed consent.

\section{Questionnaires}

The first questionnaire sent in 2017 included questions about the subject's household, pets, moisture damage both in their workplace and at home, family incomes, occupation, physical activity, smoking history, alcohol consumption, current medications, recent (within 1 month) somatic symptoms, as well as all disorders diagnosed by a doctor and general health-related questions. The questions were mainly

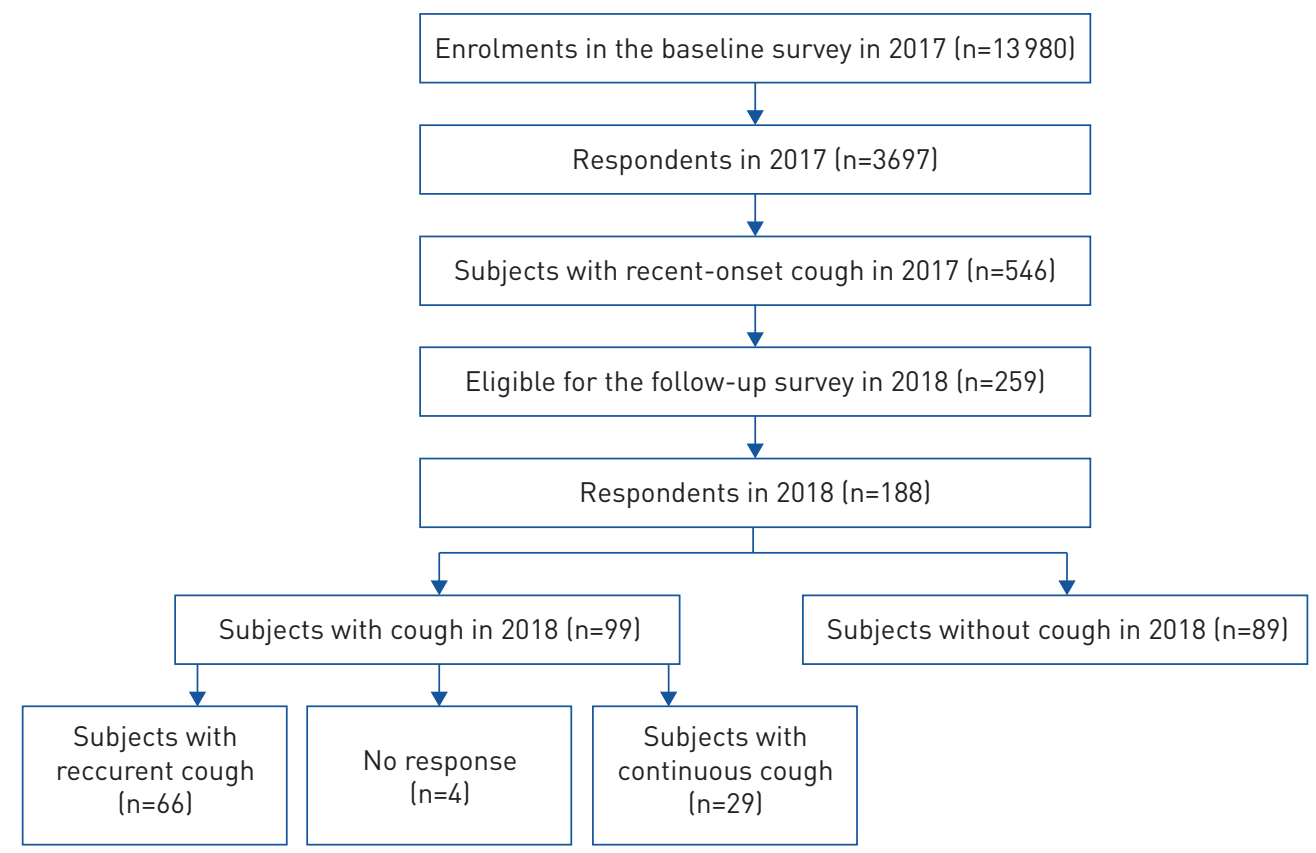

FIGURE 1 Flow chart of the study population. 
adopted from two previous studies, the Health Behaviour and Health among the Finnish Adult Population study [8] and the Finnish National FINRISK study [9]. Asthma-, rhinosinusitis- and reflux-related symptoms were investigated using questions currently suggested for epidemiological studies [10-12]. Depressive symptoms were investigated by utilising the Patient Health Questionnaire-2 (PHQ-2) [13]. The first questionnaire also included 23 detailed cough-related questions to be filled in by subjects reporting current cough, such as questions about the frequency of coughing bouts and cough duration, as well as the Leicester Cough Questionnaire (LCQ), which was used to measure cough-related quality of life [14].

The second questionnaire, sent in 2018, included questions about current cough, current smoking, current moisture damage both at the workplace and at home, current pets, and current medications. Both questionnaires were first tested in a preliminary sample of 25 subjects and slightly revised before the final study. The questionnaires can be found in the supplementary material.

\section{Definitions based on 2017 questionnaire}

Recent-onset cough was defined as cough that had lasted for $<8$ weeks. Wheezing was defined as any wheezing occurring during the previous 12 months [10]. Chronic rhinosinusitis was present if there was either nasal blockage or nasal discharge (anterior or posterior nasal drip) and either facial pain/pressure or reduction/loss of smell for $>3$ months [11]. Gastro-oesophageal reflux disease was present if there was heartburn and/or regurgitation on $\geqslant 1$ day per week during the last 3 months [12]. Depression was defined as a PHQ-2 score $\geqslant 3$ [13]. The somatic symptom score was calculated by summing all reported somatic symptoms except cough (including chest pain on exercise, joint pain, back pain, toothache, leg swelling, varicose veins, rash, headache, sleeplessness, depression, other mental health problems, constipation, other gastrointestinal discomfort and sciatica); it had a scale ranging from 0 to 14 . The presence of cough triggers refers to the phenomenon that one or more of these triggers would either cause or worsen the cough: common cold, cold weather, physical exercise, car fumes, poor indoor air quality, presence of animals, pollens, tobacco smoke and strong odours or smells. A family history of chronic cough was defined as the presence (now or in the past) of chronic (duration $>8$ weeks) cough in parents, sisters or brothers.

\section{Outcomes based on 2018 questionnaire}

The main outcome was any cough at 12 months. The secondary outcomes were recurrent cough at 12 months and continuous cough at 12 months. Any cough was defined as a current cough with any bout frequency and of any duration in 2018. Continuous cough was defined as current cough that had lasted without any interruptions from the 2017 survey up to 2018. Recurrent cough was defined as current cough at 12 months with interruptions during the last 12 months.

\section{Statistical analysis}

Descriptive data is presented as means and 95\% confidence intervals. Mann-Whitney tests and Chi-squared tests were applied when appropriate. The following confounders were considered based on plausible biological associations with cough: age, sex, body mass index (BMI), years of education, professional status, unemployment and layoff, family income, number of family members, pet ownership, ownership of dog and cat, exposure to moisture damage in the home or in the workplace, smoking history, alcohol consumption (total doses per week), family history of chronic cough, acetylsalicylic acid intolerance, somatic symptom score, the history of previous episodes of prolonged ( $>8$ weeks) cough, the presence of any cough trigger, the use of cough remedies, cough bout frequency, cough duration $<3$ or $>3$ three weeks, LCQ total score, wheezing, chronic rhinosinusitis and gastro-oesophageal reflux disease. Confounders with a prevalence $<10$ were not considered. The proportion of missing values was $<1 \%$. The variables showing at least a suggestive $(\mathrm{p}<0.1)$ association with the outcome variables in the bivariate analyses were included in the multivariate analysis utilising binary logistic regression analysis with a backward directed stepwise process. A p-value $<0.05$ was accepted as the level of statistical significance but results showing a suggestive association $(\mathrm{p}<0.1)$ are also presented. All analyses were performed using SPSS version 22 for the personal computer (SPSS Inc., Chicago, IL, USA).

\section{Results}

The response rate was $72.6 \%$ (188 subjects, mean (95\% CI) age 50.08 (10.4) years, 84\% females) (table 1). In 2018, there were 99 subjects (52.7\%) with any cough, 29 subjects (15.4\%) with continuous cough and 66 subjects $(35.1 \%)$ with recurrent cough. Four subjects did not report the duration of their cough.

Table 1 presents the factors that predicted any cough in 2018 in the bivariate analysis. Both continuous and recurrent cough were predicted $(\mathrm{p}<0.1)$ by age (in years), somatic symptom score, BMI $>25 \mathrm{~kg} \cdot \mathrm{m}^{-2}$, wheezing, cough trigger, duration of cough 3-8 weeks and LCQ total score. In addition to these, the number of family members, moisture damage in the workplace, chronic rhinitis and gastro-oesophageal 
TABLE 1 The bivariate associations between characteristics at baseline in 2017 and presence of any cough at the 12-month follow-up

Characteristic at baseline
Family history of chronic cough
History of previous episodes of prolonged cough
Cough trigger
Wheezing
Chronic rhinitis
Gastro-oesophageal reflux disease
Age years
Males
BMI $>25 \mathrm{~kg} \cdot \mathrm{m}^{-2}$
Duration of cough $3-8$ weeks
Somatic symptom score
LCQ total score
Dog ownership
Education years
Family members

\section{Subjects with any cough} at follow-up (n=99)
Subjects without any
cough at follow-up ( $n=89$ )

$56.1 \%$
$29.3 \%$
$85.9 \%$
$72.7 \%$
$32.3 \%$
$18.2 \%$

$51.5(49.6-53.3)$

$14.1 \%$

$67.7 \%$

$42.4 \%$

$3.74(3.31-4.16)$

$14.9(14.28-15.53)$ $36.4 \%$

$15.9(15.35-16.41)$

$1.68(1.42-1.94)$
$37.1 \%$

$14.6 \%$

$61.8 \%$

$43.2 \%$

$16.9 \%$

$7.9 \%$

$48.5(46.5-50.6)$

$18.0 \%$

$46.6 \%$

$27.0 \%$

$2.57(2.22-2.92)$

$16.1(15.53-16.67)$

$21.3 \%$

$16.5(16.01-17.07)$

$1.89(1.65-2.13)$ p-value

0.009

0.016

$<0.001$

$<0.001$

0.014

0.038

0.035

0.473

0.004

0.027

$<0.001$

0.006

0.024

0.084

0.089

Data are presented as mean $(95 \% \mathrm{CI})$ unless otherwise stated. Characteristics with at least suggestive association ( $p<0.10)$ and sex are presented. BMI: body mass index; LCQ: Leicester Cough Questionnaire.

reflux disease predicted only continuous cough whereas education (in years), dog ownership and a family history of chronic cough predicted only recurrent cough in the bivariate analysis.

The following factors were associated with any cough in the final stepwise model: wheezing, dog ownership, duration of cough $>3$ weeks in 2017, a family history of chronic cough, BMI $>25 \mathrm{~kg} \cdot \mathrm{m}^{-2}$ and somatic symptom score (table 2). The risk factors were completely different between continuous cough (table 3) and recurrent cough (table 4).

From 2017 to 2018, current smoking status had changed in $0.5 \%$ of subjects, current pet ownership status in $10.6 \%$ of subjects and current moisture damage exposure status in $30.3 \%$ of subjects. Nonetheless, the inclusion of these factors into the multivariate analyses did not significantly change the results.

\section{Discussion}

In the present population consisting of employed, working-age subjects with recent-onset cough, the majority (52.7\%) of subjects reported suffering from cough 12 months later. Continuous (>12 months) cough was present in $15.4 \%$ of subjects; recurrent ( $<12$ months) cough was present in $35.1 \%$ of the subjects. In the multivariate analysis, wheezing, dog ownership, duration of cough $>3$ weeks in 2017, family history of chronic cough, BMI $>25 \mathrm{~kg} \cdot \mathrm{m}^{-2}$ and somatic symptom score predicted any cough at 12 months. Interestingly, the predictive factors for continuous and recurrent cough seem to be completely different, indicating that there are different mechanisms behind these phenomena.

TABLE 2 Multivariate adjusted odds ratios (aORs) between characteristics at baseline in 2017 and presence of any cough at 12-month follow-up

\begin{tabular}{lcc} 
Characteristic at baseline & aOR (95\% Cl) & p-value \\
\hline Wheezing & $2.80(1.37-5.72)$ & 0.005 \\
Dog ownership & $2.56(1.21-5.44)$ & 0.014 \\
Duration of cough 3-8 weeks & $2.29(1.11-4.76)$ & 0.026 \\
Family history of chronic cough & $2.20(1.13-4.30)$ & 0.021 \\
BMI >25 $\mathbf{~ k g} \cdot \mathbf{m}^{-2}$ & $2.06(1.02-4.15)$ & 0.043 \\
Somatic symptom score ${ }^{\#}$ & $1.36(1.13-1.64)$ & 0.001 \\
\hline BMI: body mass index. ${ }^{\#}:$ aOR is expressed per somatic symptom. &
\end{tabular}


TABLE 3 Multivariate adjusted odds ratios (aORs) between characteristics at baseline in 2017 and presence of continuous cough" at 12 -month follow-up

\begin{tabular}{lcc} 
Characteristic at baseline & aOR (95\% CI) & p-value \\
\hline Trigger lany) & $7.87(1.59-38.90)$ & 0.011 \\
BMI > $\mathbf{2 5} \mathbf{~ k g} \cdot \mathbf{m}^{-2}$ & $5.33(1.70-16.67)$ & 0.004 \\
Gastro-oesophageal reflux disease & $4.35(1.19-15.91)$ & 0.026 \\
LCQ total score & $0.79(0.661-0.932)$ & 0.006
\end{tabular}

The subjects without any cough in 2018 served as a reference group. BMI: body mass index; LCQ: Leicester Cough Questionnaire. \#: cough that has lasted, without any interruptions, from the 2017 survey up to $2018(n=29)$; ๆ: aOR is expressed per one-point increase in LCQ.

Wheezing strongly predicted any cough. Asthma is well known to be one of the three most common reasons for chronic cough [2]. The present study extends these findings by showing that wheezing in patients who suffer from recent-onset cough may also predict the cough becoming chronic. Given its strong predictive value, the presence of wheezing should be enquired about in a patient who suffers from recent-onset cough. It could be postulated that early intervention with inhaled corticosteroids could prevent the cough from becoming a long-term problem. This kind of finding has been described in children: prednisolone has been claimed to be beneficial in preventing asthma in first-time wheezing children whose infection episode is severe and whose rhinovirus load is high [15].

Surprisingly, dog ownership was also a strong predictive factor for any cough. According to a systematic review, pets, especially dogs, may reduce the development of allergic disease in those without a family history of allergy [16]. The allergy status of the present subjects is unknown. It seems likely that a proportion of the present population was allergic to dogs, which may explain the association between dog ownership and the prolongation of cough. Based on these findings, it might be advisable to perform allergy skin tests in certain subjects with recent-onset cough. The difficult question remains of how to deal with a dog if a subject who suffers from recent-onset cough is found to be allergic to dogs.

In our study, the duration of cough for $>3$ weeks worsened the prognosis. Traditionally, recent-onset cough has been divided into acute ( $<3$ weeks) cough and subacute ( $3-8$ weeks) cough [17]. The present study validates this classification by showing that a cough with $>3$ weeks' duration is indicative that the individual will experience a long-standing problem. In fact, acute respiratory viral infections usually recover spontaneously during the first 3 weeks after the infection. If the cough lasts $>3$ weeks, it could be hypothesised that it may be a sign of an altered function of the cough reflex arc. Consequently, a cough lasting $>3$ weeks may be an indication for further investigations.

A family history of chronic cough was a predicting factor for both any cough and prolonged cough at 12 months. A family history of chronic cough was also a risk factor for a cough of any duration in our previous cross-sectional study [18]. As far as we are aware, these are the first studies to report these interesting findings. The background and mechanism behind this finding are unclear; is there a genetically driven mechanism or a common lifestyle-mediated factor?

Overweight $\left(\mathrm{BMI}>25 \mathrm{~kg} \cdot \mathrm{m}^{-2}\right.$ ) predicted any cough at 12 months. The association between obesity and cough is not well established. In a study by ZuTLER et al. [19], obesity (BMI $\geqslant 30 \mathrm{~kg} \cdot \mathrm{m}^{-2}$ ) was associated

TABLE 4 Multivariate adjusted odds ratios (aORs) between characteristics at baseline in 2017 and presence of recurrent cough ${ }^{\#}$ at 12 -month follow-up

\begin{tabular}{lcc} 
Characteristic at baseline & aOR (95\% CI) & p-value \\
\hline Wheezing & $2.85(1.34-6.09)$ & 0.007 \\
Family history of chronic cough & $2.25(1.10-4.60)$ & 0.027 \\
Duration of cough 3-8 weeks & $2.22(0.99-4.21)$ & 0.055 \\
Dog ownership & $2.09(0.95-4.59)$ & 0.066 \\
Somatic symptom score & $1.31(1.08-1.58)$ & 0.006
\end{tabular}

The subjects without any cough in 2018 served as a reference group. \#: current cough at 12 months with interruptions during the last 12 months $(n=66) ;{ }^{~}$ : aOR is expressed per somatic symptom. 
with an increased risk of productive cough. In our previous study, a high BMI was associated with a poor prognosis of chronic cough [3]. There are also some population-based studies that have detected an association between obesity and chronic cough [20,21]. Interventions to reduce body weight might be an option to decrease the risk of cough prolongation in recent-onset, overweight coughers.

In this study, the number of somatic symptoms predicted the presence of cough at 12 months. It seems likely that there are individual differences in the ways in which individuals recognise and report their symptoms, a phenomenon called somatisation. In the present study, somatisation was taken into account by calculating the somatic symptom score.

Interestingly, the risk factors for recurrent and continuous cough were completely different. The presence of a cough trigger, BMI $>25 \mathrm{~kg} \cdot \mathrm{m}^{-2}$, gastro-oesophageal reflux disease and the LCQ total score predicted continuous cough. In contrast, wheezing, a family history of chronic cough, duration of cough $>3$ weeks, dog ownership and the somatic symptom score were predictive of recurrent cough. The presence of cough triggers in continuous cough may indicate a long-standing abnormality in the cough reflex arc. Therefore, the most urgent interventions should be focused on these individuals, such as antireflux treatment and intentional weight loss. In turn, antiasthma treatment might prevent cough prolongation in patients with wheezing, a family history of chronic cough and prolongation of cough $>3$ weeks.

There are several limitations to the present study. The sample size could have been larger. The population consisted of working-age, public service employees so the generalisability of the study may be limited. Individuals in lower social classes and old persons are therefore underrepresented, and this may also partly explain the low smoking rate. Thus, the role of smoking in cough prolongation cannot be determined in this population. It should also be taken into account that the study is based on self-reported symptoms, not on doctor-diagnosed diseases.

The strengths of the study include its prospective, follow-up study design. It is recognised that causal inference between risk factors and cough prolongation can be better investigated in a prospective, follow-up study than in one with a cross-sectional design. The baseline questionnaire was comprehensive and the collection of risk factors was systematic. The response rate was satisfactory. Furthermore, the present study design enabled the collection of a sufficient number of subjects with recent-onset cough. To the best of our knowledge, this kind of study has never been conducted before in cough sufferers. It would be difficult to recruit as many subjects with recent-onset cough with any other type of study design. The questionnaire was sent out in March and April to minimise the influence of respiratory infections or seasonal allergens.

In conclusion, as many as 50\% of recent-onset coughers still report the presence of a cough 12 months later. The present study describes the factors that predict cough prolongation in individuals with recent-onset cough. There were two different types of cough prolongation with completely different risk factors. These factors might help physicians to select patients who need special interventions. Further studies will be needed to define whether early interventions in individuals experiencing recent-onset cough can prevent the cough from becoming chronic.

Acknowledgements: We thank Seppo Hartikainen (Istekki Oy, Kuopio, Finland) for his assistance in creating the electronic questionnaire.

Conflict of interest: A.M. Lätti reports grants from Kuopion Hengityssäätiö Foundation and Hengityssairauksien Tutkimussäätiö during the conduct of the study, and personal fees from Orion, Boehringer-Ingelheim and Roche to attend international scientific meetings outside the submitted work. J. Pekkanen has nothing to disclose. H.O. Koskela reports grants from Kuopion Hengityssäätiö Foundation and Hengityssairauksien Tutkimussäätiö during the conduct of the study; and personal fees from Mundipharma Ltd, Orion Pharma Ltd, Oy, Eli Lilly Finland Ltd and Boehringer Ingelheim Finland Ltd as payments for giving scientific lectures at gatherings organised by medical companies, personal fees from Takeda Leiras Ltd, Boehringer Ingelheim Ltd, Mundipharma Ltd and AstraZeneca Ltd to attend international scientific meetings, and owning shares in Orion Pharma Ltd worth $€ 22000$.

Support statement: The study was funded by grants from the Kuopion Hengityssäätio and Hengityssairauksien Tutkimussäätiö foundations. They had no input in the development of the research and manuscript. Funding information for this article has been deposited with the Crossref Funder Registry.

\section{References}

1 Wandell P, Carlsson AC, Wettermark B, et al. Most common diseases diagnosed in primary care in Stockholm, Sweden, in 2011. Fam Pract 2013; 30: 506-513.

2 Chamberlain SA, Garrod R, Douiri A, et al. The impact of chronic cough: a cross-sectional European survey. Lung 2015; 193: 401-408.

3 Koskela HO, Latti AM, Purokivi MK. Long-term prognosis of chronic cough: a prospective, observational cohort study. BMC Pulm Med 2017; 17: 146.

4 Ryan NM, Vertigan AE, Birring SS. An update and systematic review on drug therapies for the treatment of refractory chronic cough. Expert Opin Pharmacother 2018; 19: 687-711. 
5 Chung KF. Chronic "cough hypersensitivity syndrome": a more precise label for chronic cough. Pulm Pharmacol Ther 2011; 24: 267-271.

6 Morice AH. Chronic cough hypersensitivity syndrome. Cough 2013; 9: 14.

7 Koskela HO, Lätti AM, Pekkanen J. The impacts of cough: a cross-sectional study in a Finnish adult employee population. ERJ Open Res 2018; 4.

8 National Institute for Health and Welfare. Health Behaviour and Health among the Finnish Adult Population. National Institute for Health and Welfare. Health Behavi. https://thl.fi/en/tutkimus-ja-kehittaminen/tutkimuksetja-hankkeet/aikuisten-terveys-hyvinvointi-ja-palvelututkimus-ath/aiemmat-tutkimukset/suomalaisen-aikuisvaestonterveyskayttaytyminen-ja-terveys-avtk

9 National Institute for Health and Welfare. The National FINRISK Study. https://thl.fi/en/web/thlfi-en/researchand-expertwork/population-studies/the-national-finrisk-study

10 Sa-Sousa A, Jacinto T, Azevedo LF, et al. Operational definitions of asthma in recent epidemiological studies are inconsistent. Clin Transl Allergy 2014; 4: 24

11 Fokkens WJ, Lund VJ, Mullol J, et al. European position paper on rhinosinusitis and nasal polyps 2012. Rhinol Suppl 2012; 50: 1-298.

12 El-Serag HB, Sweet S, Winchester CC, et al. Update on the epidemiology of gastro-oesophageal reflux disease: a systematic review. Gut 2014; 63: 871-880.

13 Kroenke K, Spitzer RL, Williams JB. The Patient Health Questionnaire-2: validity of a two-item depression screener. Med Care 2003; 41: 1284-1292.

14 Birring SS, Prudon B, Carr AJ, et al. Development of a symptom specific health status measure for patients with chronic cough: Leicester Cough Questionnaire (LCQ). Thorax 2003; 58: 339-343.

15 Koistinen a, Lukkarinen M, Turunen $\mathrm{R}$, et al. Prednisolone for the first rhinovirus-induced wheezing and 4-year asthma risk: a randomized trial. Pediatr Allergy Immunol 2017; 28: 557-563.

16 Lodge CJ, Allen KJ, Lowe AJ, et al. Perinatal cat and dog exposure and the risk of asthma and allergy in the urban environment: a systematic review of longitudinal studies. Clin Dev Immunol 2012; 2012: 176484.

17 Irwin RS, French CL, Chang AB, et al. Classification of cough as a symptom in adults and management algorithms: CHEST guideline and expert panel report. Chest 2018; 153: 196-209.

18 Lätti AM, Pekkanen J, Koskela HO. Defining the risk factors for acute, subacute and chronic cough: a cross-sectional study in a Finnish adult employee population. BMJ Open 2018; 8: e022950.

19 Zutler M, Singer JP, Omachi TA, et al. Relationship of obesity with respiratory symptoms and decreased functional capacity in adults without established COPD. Prim Care Respir J 2012; 21: 194-201.

20 Corbo GM, Forastiere F, Rusconi F, et al. Dietary habits, life styles and respiratory symptoms in childhood. Epidemiol Prev 2005; 29: 42-46.

21 Liu Y, Pleasants RA, Croft JB, et al. Body mass index, respiratory conditions, asthma, and chronic obstructive pulmonary disease. Respir Med 2015; 109: 851-859. 